\title{
Indicadores de marketing digital para websites de arquivos públicos estaduais
}

\author{
Luan Henrique Giroto Ferreira \\ Mestrando; Universidade Estadual Paulista Júlio de Mesquita Filho, Marília, SP, Brasil; \\ luan.giroto@gmail.com \\ Rosângela Formentini Caldas \\ Doutora; Universidade Estadual Paulista Júlio de Mesquita Filho, Marília, SP, Brasil; \\ rcaldas@marilia.unesp.br
}

\begin{abstract}
Resumo: A web como contexto de novas formas de comunicação e interação informacional permite potencializar as unidades arquivísticas. O marketing adapta-se aos meios digitais a fim de conquistar outros mercados e satisfazer com melhor precisão as necessidades do público-alvo. A pesquisa se justifica diante dos poucos estudos existentes dessa natureza na área de ciência da informação e acredita-se que os resultados corroboram no desenvolvimento do marketing digital para instituições informacionais. Assim, tende a ser problemática da pesquisa o acesso à informação mediante o marketing digital para arquivos públicos estaduais. O objetivo do estudo investigativo propôs analisar websites de arquivos públicos estaduais e do Arquivo Nacional e arquivos do Distrito Federal com o intuito de verificar a promoção institucional através do marketing digital e a disseminação informacional realizada através dos espaços virtuais enquanto formação de um ambiente eletrônico. O estudo é de abordagem qualitativa, com a metodologia de estudo de caso do ambiente digital das unidades de informação realizando uma análise comparativa entre os websites dos Arquivos averiguados.
\end{abstract}

Palavras-chave: Marketing digital. Arquivos. Difusão. Indicadores. Web 2.0.

\section{Introdução}

Os arquivos utilizam a internet como meio de propagação de suas atividades, tendo em vista a legislação nacional sobre o acesso e o uso da informação em âmbito público. Nesta via, o website institucional é um meio no qual os arquivos públicos e nacionais encontram aberturas que facilitam o compartilhamento de informações na internet. 
Diante das iniciativas de valorização da informação, o marketing digital favorece as atividades concernentes aos arquivos como: guarda, descrição e acesso, proporcionando ações de melhorias para a disponibilização e gerenciamento informacional, integrando a difusão em redes.

A atuação em marketing digital em instituições arquivísticas deve ancorar estratégias diferenciadas face aos múltiplos desafios por elas enfrentados, como, por exemplo, a falta de recursos, de políticas públicas, de atuação profissional na área e, ainda, uma difícil ruptura com a custodialidade. Esses fatores evidenciam o importante processo educativo e gerencial a ser consolidado para que as organizações possam atingir tópicos processuais, conhecer os públicos e as suas necessidades de informações.

Sendo assim, o estudo que origina este artigo consiste em averiguar os arquivos públicos estaduais do Brasil e o Arquivo Nacional quanto ao uso eficiente do marketing digital. Entendeu-se que estruturar uma estratégia de difusão da informação poderá oferecer acesso que proporcionará uma visibilidade melhor da instituição arquivística na internet. Evidenciam-se os arquivos públicos estaduais, pois são referências em ações, técnicas arquivísticas e regulam questões relacionadas à gestão e à preservação de documentos públicos produzidos e acumulados por órgãos e entidades públicas para além de realizar importante papel no tangente a Lei de Acesso à Informação. O Arquivo Nacional e o Arquivo do Distrito Federal contribuem para o desenvolvimento de ações legais de disponibilização e o uso da informação pelos Estados.

Ressalta-se que estudos sobre marketing digital em meio arquivístico auxiliariam a fomentar a administração de conteúdos, uma vez que são poucas as pesquisas nesse âmbito. Outro enquadramento que pode ser contemplado durante o desenvolvimento dessa pesquisa é o aperfeiçoamento de estudos que envolvam o arquivo no mercado baseado na informação e na tecnologia. Tal tendência aponta para as estratégias para que a difusão informacional da instituição na web possa atingir ambientes como: o tecnológico, o político, o social e o cultural da sociedade.

O estudo tem por objetivo geral analisar o marketing digital em websites de arquivos públicos estaduais e no Arquivo Nacional e do Distrito Federal. 
Como objetivos específicos busca entender questões conceituais do marketing que podem ser aplicados no contexto arquivístico; verificar os conhecimentos relacionados ao marketing em ambiente digital; detalhar indicadores que possam influenciar o ambiente digital aos quais os arquivos públicos estaduais e o Arquivo Nacional e do Distrito Federal encontram-se inseridos; e oferecer subsídios de estudos futuros em marketing para arquivos.

Quanto à metodologia da pesquisa de natureza qualitativa, ela é exploratória e descritiva a partir de revisão bibliográfica e exploratória básica. A partir de múltiplos estudos de casos, foram propostos indicadores de marketing digital para arquivos, o que resultou em planilha com endereços eletrônicos listados pelo Conselho Nacional de Arquivos (CONARQ).

A metodologia foi determinante para alcançar o objetivo da pesquisa. Para tanto, verificou-se que 27 (vinte e sete) instituições são listadas pelo CONARQ. A análise de dados contou com: análise comparativa e descritiva. Como resultado advindo do estudo, compreendeu-se existir uma colaboração entre o marketing digital e os arquivos, bem como cooperar para o gerencialmente eficaz de informações e para novas formas de interação, relacionamento e valores sociais no contexto dos arquivos na internet.

\section{Marketing em unidades arquivísticas}

Apesar de toda evolução histórica do termo, o marketing é compreendido como conhecimento para vendas, sendo que seu campo científico é interdisciplinar. As organizações, lucrativas e não lucrativas, com seus bens tangíveis e não tangíveis, com serviços e clientes, tendem a assumir o termo das mais diversas maneiras. "Marketing significa administrar mercados para dar oportunidade a trocas e relacionamentos, com o propósito de criar valor e satisfazer necessidades e desejos." (KOTLER; ARMSTRONG, 1997, p. 7).

Os conhecimentos de marketing são aplicados com mais ênfase no âmbito das bibliotecas por abranger um público-alvo cativo e, assim, permitir ações que valorizam os serviços e produtos já consolidados pela sociedade à medida que supram os desejos e as necessidades dos indivíduos. Entretanto, o 
marketing, quando trabalhado para os variados equipamentos culturais, promove uma filosofia que permite uma imagem dinâmica e positiva da instituição, de forma a "[...] criar, desenvolver, promover e distribuir produtos e serviços da informação a serem consumidos e utilizados pelos usuários." (OLIVEIRA; PEREIRA, 2003, p. 14).

Assim, o marketing pode agregar aos arquivos um novo meio de compreender e analisar seus pontos fracos e fortes perante um mercado de constante mutação e inovação para a transferência de informação. Para Hair (2014), o marketing identificará oportunidades estratégicas em prol de melhores resultados em serviços prestados à comunidade. De tal modo, as unidades arquivísticas poderão inserir o marketing como filosofia administrativa e ação de gerenciamento da informação capaz de atender às necessidades e os desejos dos sujeitos, que tendem a exigir com melhor precisão seus benefícios e direitos.

Neste contexto, Amaral (1998) destaca a importância do produto - a informação - no fluxo interno e externo à instituição e que, portanto, assume uma responsabilidade no tangente da sua organização, reconhecendo as aplicações de marketing para oferecer estratégias de consolidação.

A razão primordial de as organizações que não visam ao lucro se interessarem pelo marketing, é decorrente da possibilidade de a organização tornar-se mais eficaz, tanto no alcance dos seus objetivos, como na obtenção de recursos, ainda que denominem dessa maneira suas relações de troca com o meio ambiente. (KOTLER, $1978^{1}$, p. 24 apud AMARAL, 1998, p. 64).

Para o marketing nas instituições arquivísticas, as vantagens são inúmeras. Desde a visibilidade institucional, promoção, reconhecimento em diferentes esferas administrativas para além de incorporar questões sobre a importância do arquivo para a democracia e o funcionamento dos Estados. Entretanto, sua aplicabilidade como atividade concreta poderá ser em maior ou menor grau dependendo das características de cada instituição (ROSELL, 2006).

Gradativamente, o acesso à informação diante do valor cultural e histórico para a sociedade torna-se, em maior grau, um estímulo para a pesquisa e para a disponibilização de conteúdo, mas que, necessariamente, deverão ser filtradas para atender às necessidades do sujeito. 
Assim, os arquivos começam a atuar em segmentos que não dominavam, ampliando deste modo, o mercado de atuação e formando parcerias para oferecer serviços completos e dinâmicos por meio da difusão. "Instituições com visão de futuro estão mudando cada vez mais seu foco de categorias de mercado-produto, com definição estreita para a totalidade das experiências dos clientes em espaço de mercado." (MENEZES, 2013, p. 59).

Segundo Menezes (2013), o mercado é contextualizado perante a ligação dos clientes e não só com os produtos. Na internet, as propagações da instituição e do acervo tornaram-se mais rentáveis diante da difusão da informação pelos canais de comunicação, tais como o website e mídias sociais. Isso se dá pela mudança social adotada e difundida pelas tecnologias, que viabilizam a informação em diversos cenários e meios comunicativos para fornecer o produto ao cliente. O e-commerce é um exemplo de difusão consolidada que alterou o sistema social e todo desenvolvimento comunicacional utilizado por empresas e sujeitos.

Desse modo, “A difusão é uma das funções arquivísticas essenciais para que se cumpra o acesso à informação.” (MENEZES, 2013, p. 52). Dentre as variáveis, destacam-se: palestras, publicação de instrumentos de pesquisas, visitas guiadas, exposições, cursos e páginas na internet. Para Blaya Perez (2008), o processo de difusão tem como objetivo principal disponibilizar informações para o maior número de pessoas e que já está implícito nas atividades desenvolvidas dentro da maioria das instituições arquivísticas.

Relacionando o marketing com a difusão, chega-se a uma relação influenciada por fatores tecnológicos para o uso, percepção, influência e adoção de novas ações que facilitem o compartilhamento de informação. Para Van Den Akker (2011), as instituições de patrimônio público devem repensar o formato de seus produtos e serviços, renovando tarefas tradicionais de informação em recursos interativos e com diálogo aos sujeitos.

Como meio de orientar as unidades arquivísticas na Web, o CONARQ ${ }^{2}$ elaborou diretrizes referentes aos arquivos na dimensão virtual com o objetivo básico que consiste em criar um referencial para as instituições, sugerindo diretrizes que reflitam na construção e redefinição de websites. 
Tais propostas do CONARQ são contribuintes no âmbito do marketing digital em arquivos, por atender as necessidades de disponibilização de informações do campo da Arquivologia como estratégias na Web.

\section{Marketing em ambientes digitais}

A internet passou por diversas modificações até chegarmos à interatividade e relacionamento virtual que se evidencia atualmente. Não somente a rede foi modificada, mas todo o sistema social foi "aprimorado" de forma a agregar as mídias sociais para uma interação colaborativa.

Os primeiros estágios do uso da internet, na década de 1980, foram anunciados como a chegada de uma nova era de comunicação livre e realização pessoal nas comunidades virtuais formadas em torno da comunicação mediada pelo computador (CASTELLS, 2001, p.100).

Com a Web $2.0^{3}$, para além da disseminação da informação, a comunicação integrada a outras ferramentas colaborativas e de interação como, por exemplo, as mídias sociais e os canais de disponibilização de vídeos, permitiram a reconfiguração do ambiente Web no que se refere ao contexto de marketing. Para Fleury (2001),

A internet traz consigo uma ideia revolucionaria para o marketing: o fato de que o consumidor vai em busca do anunciante, em vez do anunciante ir em busca do consumidor. Dessa forma, neste novo mercado tudo acontece de maneira diferente. (FLEURY, 2001, p. 44).

A comunicação digital na Web 2.0 interliga a internet com a cibercultura proposta por Lévy (2000). Entretanto, o dinâmico ambiente permite que a expansão tecnológica ofereça novas oportunidades para o marketing em sua adesão à internet como estratégias para a preservação, compartilhamento e difusão de informações de interesse público. O desafio é construir conteúdos que norteiem os princípios de marketing digital apoiados nos objetivos dos arquivos e nas necessidades dos agentes. 
O conceito de marketing digital se distingue por conter variáveis terminológicas, entre elas: E-marketing, marketing na internet, marketing online ou marketing digital. "E-marketing consiste no uso da tecnologia de informação para atividades de marketing, e os processos para criar, comunicar, desenvolver e compartilhar ofertas que agregam valor aos clientes, parceiros e a sociedade em geral.” (STRAUSS; FROST, 2012, p. 6).

Já para outro autor, "As estratégias de marketing na internet [...] tratam de uma nova tecnologia para melhorar a eficácia e a eficiência de estratégias e práticas de marketing existente." (ANGEHRN, 2001, p. 271).

Outra definição, denominada como marketing digital, adentra em diretrizes que fomentam o termo:

[...] as grandes forças do marketing digital são: interatividade, personalização, globalização, integração, aproximação, convergência e democratização da informação. Cada uma oferece uma nova dimensão à comunicação, às vendas e ao relacionamento com o mercado. (CHLEBA, 1999, p. 19).

As implementações advindas das tecnologias de informação e comunicação (TIC) como estratégia de marketing digital geram oportunidades de crescimento organizacional afinal, os agentes mudaram os perfis tradicionais com elevadas expectativas em relação à comunicação com as instituições. $\mathrm{Na}$ Figura 1, verifica-se que Strauss e Frost (2012) apontam, segundo uma pesquisa feita no Reino Unido através do website governamental BusinessLik, as oportunidades e mudanças do "novo marketing".

\section{Figura 1 - Representação de conceitos do marketing digital}

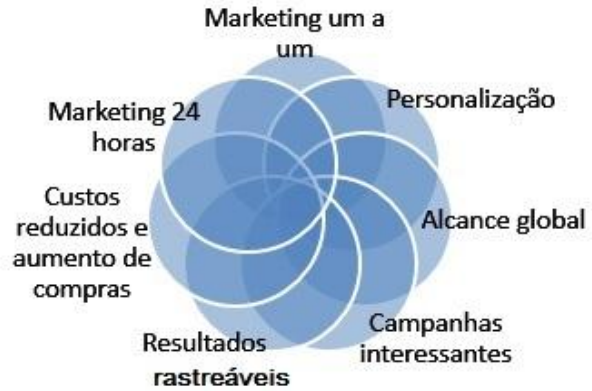

Fonte: Elaborado pelos autores. 
Novos públicos e meios convergentes de comunicação enfatizam os pilares do marketing digital, garantindo que todos os recursos disponíveis na Web sejam utilizados para ações estratégicas como forma de interação e de relacionamento com o usuário potencial. Nos arquivos, o marketing digital permite estabelecer trocas e relacionamentos com o cliente mediante o uso da tecnologia. Segundo Menezes (2013, p. 57) "O marketing digital permite interligar funções e divulgar os serviços e produtos disponíveis, o usuário passa a ter acesso quase que instantâneo a qualquer tipo de informação, no momento em que considera mais oportuno".

Neste contexto tecnológico, os autores Zeisser e Waitman (1998) desenvolveram cinco diretrizes de como fomentar o Marketing Digital. São elas:

1. Atrair usuários; 2. Os usuários devem exercer participação e interesse; 3. Garantir que os usuários retornem para o aplicativo;4. Saber sobre suas preferências; 5. Relativa volta para os usuários fornecerem interações personalizadas que representam o verdadeiro "valor bolha" de marketing digital. (ZEISSER; WAITMAN, 1998, p.34, tradução nossa).

A mudança de cenário trouxe possibilidades enriquecedoras para o cenário atual, acrescentando propostas impulsionadas pelo contexto digital, na quais as instituições disseminem e gerenciem informações pela internet ao seu público.

Em pesquisas às homepages de instituições arquivísticas na região sul do Brasil, Menezes (2013) apresentou como resultado de sua investigação o alto índice de desatualização e de acervos que não foram digitalizados para consulta online. Tendo em vista tal demonstrativo, o marketing digital quando atrelado à difusão digital merece atenção, visto que é uma ação de melhoria que apresenta benefícios para a instituição, como: visibilidade, troca de informações instantâneas, produtos específicos, fortalecimento da instituição e direcionamento de ações e serviços em rede.

As pessoas possuem certo grau de expectativa ao procurar as instituições arquivísticas, criada a partir dos processos de difusão, os quais precisam ter harmonia entre o que é prometido e o que é experimentado (MENEZES, 2013, p.69). 
O marketing digital potencializa os cenários "transformacionais”, “[...] uma contínua mudança organizacional através do consumidor-cliente que substitui a interação orientada a massa e do mundo tradicional à comunicação intermitente.” (ZEISSER; WAITMAN,1998, p. 38).

$\mathrm{Na}$ perspectiva das unidades arquivísticas, o marketing digital institui oportunidades de crescimento de relacionamento, mercado e comunicação. Mediante este contexto, o arquivo usufrui de produtos e serviços mais atraentes e mantém um contato diretamente com o cliente para informá-lo continuamente sobre a unidade e seus instrumentos de difusão em rede (OLIVEIRA; PEREIRA, 2003).

A atividade comunicativa é direcionada ao público, sem a necessidade de intermediários, o que reduz os custos para o processo de comunicação. Assim que a unidade estabeleça uma interatividade com o internauta, é indispensável manter a excelência dessas relações, oferecendo-lhes produtos e serviços de qualidade (ARAÚJO; SILVA, 2013). A adoção de logísticas específicas, produtos personalizados, preços flexíveis e o próprio marketing se reinventaram para atender as novas demandas e a complexidade do mercado digital.

\section{Metodologia}

Reconhecendo os objetivos da pesquisa e a necessidade de uma abordagem que integre a verificação, a análise e a descrição de fenômenos e teorias científicas, realizou-se, nesta investigação, uma aplicabilidade qualitativa. A natureza é de caráter exploratório e descritivo, com a metodologia da pesquisa bibliográfica para compor os indicadores de marketing digital e os estudos de casos múltiplos.

A escolha pelo método de estudo de casos múltiplos deu-se diante do objetivo da investigação que visa propor indicadores para o desenvolvimento de marketing digital em websites dos arquivos públicos estaduais da federação bem como o Arquivo Nacional e do Distrito Federal.

Para o universo de pesquisa, compreende-se que dos vinte e sete arquivos estaduais disponíveis pelo CONARQ, apenas quatorze instituições possuíam websites oficiais. São eles: Arquivo Nacional; Arquivo Público do 
Distrito Federal; Arquivo do Estado do Ceará; Arquivo Público do Estado do Espírito Santo; Arquivo Público de Mato Grosso; Arquivo Público Mineiro; Arquivo Público do Paraná; Arquivo Público do Estado do Rio de Janeiro; Arquivo Histórico do Rio Grande do Norte; Arquivo Histórico do Rio Grande do Sul; Arquivo Público do Estado do Rio Grande do Sul; Arquivo Público do Estado de Santa Catarina; Arquivo Público do Estado de São Paulo; Arquivo Público do Estado da Bahia.

Para o levantamento de dados, foram enumerados os arquivos em uma planilha de endereços eletrônicos e nome da instituição. A partir desse momento, sentiuse a necessidade de indicadores que poderiam nortear a coleta de dados nos websites. Portanto, em um primeiro momento, apoiou-se em pesquisa bibliográfica para realizar a descrição de indicadores que pudessem determinar diretrizes para a análise dos websites dos arquivos no que se refere ao marketing digital, apreendido nos conceitos propostos por Chleba (1999); Zeisser e Waitman (1998); Strauss e Frost (2012); e Menezes (2013).

Figura 2 - Indicadores de marketing digital para ambientes arquivísticos

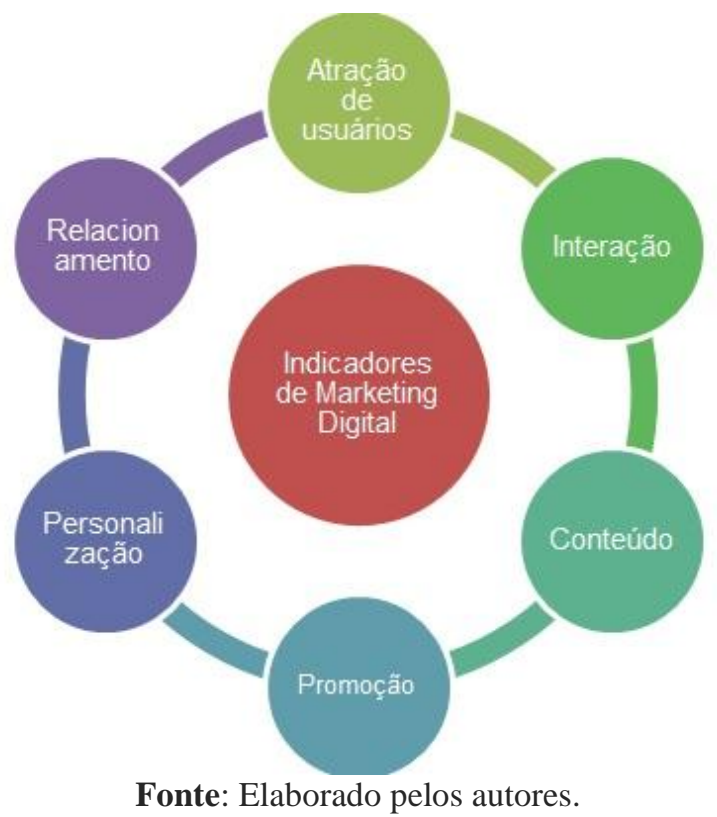




\subsection{Indicadores de marketing digital}

Considera-se o ambiente web como um espaço sociocultural que promove diálogos entre população e tecnologias. Concomitantemente, os indicadores de marketing digital podem ser utilizados pelos Arquivos a fim de que as informações dispostas nessas unidades passem a serem utilizadas de forma crítica e reflexiva pelos seus usuários, ganhando vida na medida em que geram conhecimentos.

Diante do exposto, é descrito a conjuntura de cada indicador proposto na investigação.

a) Atração de usuários

No primeiro indicador, os websites para a agregação do marketing digital devem apresentar os arquivos enquanto instituição pública na internet frente a seus propósitos, carga de serviços, publicações e os afazeres ofertados. Para Zeisser e Waitman (1998), a marca da organização deve ser fundamentada e reconhecida pelos internautas mediante o uso de hiperlinks de outros websites parceiros. Muitas das vezes, a homepage é vinculada a órgãos superiores, o que possibilita uma hipertextualidade maior, apesar de pouca interatividade.

b) Interação

A implementação de serviço online demonstra um maior interesse em relação ao público e permite interação na interface institucional. O uso de hipermídias e hipertextos propiciam uma potencialidade maior no acesso e na disponibilização dos documentos, facilitadora de uma comunicação ágil nos serviços propostos pelos arquivos.

Sob a perspectiva do marketing, "A interatividade e a personalização são elementos que podem ser explorados nos websites, em que a oferta de produtos e serviços se dá por meio de tecnologias da informação baseadas em hipertexto." (CHAIN, 2007, p. 98). 


\section{c) Conteúdo}

Os autores Zeisser e Waitman (1998) destacam que o contato permanente entre a instituição e o cliente é essencial, pois garantem, de certa forma, que os clientes voltem com mais frequência à página web. Renovar o conteúdo do website e desenvolver novas interatividades impulsionam tal retorno. A mudança de estrutura do conteúdo na homepage, pode acarretar, muitas vezes, uma nova visualização.

Amaral e Souza (2008) relatam que o website tem que estar atualizado para que o cliente visite a página mais de uma vez a fim de encontrar informações que queiram visualizar naquele espaço, ou seja, permitir a construção de um público cativo.

\section{d) Promoção}

Com a possibilidade de promover a instituição com menor custo e em longo prazo, os arquivos utilizam das plataformas digitais para divulgar todas as atividades realizadas. Para as decisões comerciais, é essencial o uso de promoção como meio de obtenção de lucros em várias ferramentas de mídias. Utilização de banners, fotos, vídeos e mídias, podem proporcionar uma função promocional na página. Uma vez disponibilizados hiperlinks ou quaisquer novas informações de maneiras criativas e úteis que facilitem a "navegação" do usuário e despertem a curiosidade dos mesmos, o marketing beneficiará novos modos de compartilhamento de informações na internet.

\section{e) Personalização}

Com a pesquisa de marketing, as instituições podem utilizar de recursos de registros digitais, tais como banco de dados dos usuários, para personalizar informações e suprir as necessidades de seu público. Os autores Strauss e Frost (2012) destacam que o banco de dados para marketing é uma estratégia que constitui a gestão do conhecimento da empresa por meio da coleta, análise e disseminação das informações eletrônicas dos usuários. 


\section{f) Relacionamento}

É possível mediante a comunicação existente entre os internautas e a instituição, que o relacionamento entre ambas sejam personalizado. Zeisser e Waitman (1998) ressaltam que ao saber as preferências e as informações relevantes dos sujeitos, pode-se apresentar e desenvolver estratégias de promoção de serviços, fidelidade à instituição, compartilhamento de informações personalizadas e um retorno que permite o crescimento da organização na internet.

Outras possibilidades são possíveis para manter um contato com o indivíduo, como estender o relacionamento por meio das mídias virtuais.

Visto os indicadores que fomentam as informações vinculadas à instituição, pode-se desempenhar ações pré-estabelecidas do composto do marketing aplicado na internet. Dessa forma, o marketing digital alcança resultados melhores, envolvendo um mercado ainda em construção com os recursos das TIC em prol do desenvolvimento do arquivo.

\subsection{Procedimentos de análise de dados}

Definidos os arquivos a serem estudados, foi realizada, a partir do contexto de indicadores propostos na pesquisa, uma análise individual nos websites dos arquivos públicos estaduais bem como do Arquivo Nacional e do Distrito Federal. Posteriormente, realizou-se a análise comparativa entre as instituições a fim de averiguar do uso potencial de ferramentas de marketing digital em arquivos.

Para todos os Indicadores propostos, foram levantadas subcategorias baseadas na literatura específica de marketing digital, sendo assim, cada indicador possui diretrizes de análise para contemplação e verificação em cada website, conforme a Figura 2. 
Figura 2 - Subcategorias dos indicadores de marketing digital

\begin{tabular}{|c|c|}
\hline $\begin{array}{l}\text { Atração de } \\
\text { usuários }\end{array}$ & $\begin{array}{l}\text { - Layouts } \\
\text { - Logomarcas } \\
\text { - História Institucional } \\
\text { - Menu }\end{array}$ \\
\hline Interação & $\begin{array}{l}\text { - Chats } \\
\text { - Comentários via Mídias sócias } \\
\text { - Serviços online } \\
\text {-E-mail }\end{array}$ \\
\hline Conteúdo & $\begin{array}{l}\text { - Atualização } \\
\text { - Conteúdos específicos } \\
\text { - Hiperlinks Outros formatos midiáticos }\end{array}$ \\
\hline Promoção & $\begin{array}{l}\text { - Campanhas } \\
\text { - Uso de hipermídias }\end{array}$ \\
\hline Personalização & $\begin{array}{l}\text { - Cadastro } \\
\text { - Pesquisa personalizada } \\
\text { - Serviços personalizados }\end{array}$ \\
\hline Relacionamento & $\begin{array}{l}\text { - Vínculo com Mídias sociais } \\
\text { - Perguntas frequentes }\end{array}$ \\
\hline
\end{tabular}

Fonte: Elaborado pelos autores.

\section{Análise de dados}

Com base nos 12 websites de arquivos públicos estaduais e dois websites baseados no Arquivo Nacional e do Distrito Federal, destacaram-se algumas afirmações referentes ao foco principal da pesquisa. Gonçalez e Jorente (2014) destacam a importância das instituições arquivísticas nos ambientes digitais sendo representadas por meio de suas homepages. Esses ambientes deveriam estar adequados às necessidades e competências dos usuários, ampliando o paradigma como: custodial e pós-custodial de acesso à informação.

A simbiose entre a informação e a tecnologia digital veio por em causa a noção estática e duradoura de "documento" (tendencialmente identificado com mensagens registradas num suporte papel) como conceito operatório e como objeto de estudo e marcou a entrada dos arquivos e da Arquivística na chamada "era pós-custodial." (RIBEIRO, 2005, p. 7).

No campo analítico do marketing digital, a atração de usuários corresponde a uma primeira impressão do cliente para com a página inicial do website arquivístico. Todavia, os agregadores de tal indicador, layout, logotipo, história e menu, necessitam de integração atrativa que permita "seduzir" um 
público mediante a facilidade de navegação existente no ambiente digital. Entretanto, os websites dos arquivos denotam outra realidade.

A falta de logomarcas dificulta o destaque da instituição em meio a outras instituições na web. Almeida (2008) esclarece que as organizações, mesmo sem fins lucrativos, devem contar com vantagens competitivas sustentáveis e resultados que possam ser relevantes na diferenciação entre si e outras. Neste sentido, a construção da imagem organizacional de um arquivo deve contemplar um logotipo que o represente no mercado digital.

Quanto aos precários menus existentes nas páginas, considera-se a carência de design da informação (KAHN; JORENTE, 2016-2017) enquanto disciplina voltada para a produção e organização do conteúdo informacional de acordo com as necessidades dos usuários (BRASILEIRO; FREIRE, 2012). Ocasionalmente, poderá afetar a forma dinâmica dos layouts contemplados no website.

A forma como a informação é disponibilizada ao sujeito refletirá em melhor ou pior comunicação dos conteúdos informacionais da página junto ao público. Parece lógico, mas a interação, outro indicador analisado, tende a provocar rupturas de transmissão de dados, informação e conhecimento na era digital (CASTELLS, 2001). Para os Arquivos, a ideia de proporcionar chats e a interoperabilidade entre seus conteúdos e mídias sociais ainda é rara.

Apesar dos 14 websites estarem com os endereços de e-mail disponíveis, os serviços prestados como mediação eletrônica ainda são insuficientes perante políticas públicas de disponibilização de conteúdos documentais.

Neste caso, os gestores dos websites deveriam reconhecer a necessidade de uma política capaz de fornecer informações constantes, de modo a se preservar e disseminar os registros de valor cultural e histórico com o uso de novas tecnologias, tornando-as acessíveis a todos. Entretanto, o que vimos em algumas páginas são “informações alienígenas” (AMARAL, 1998), incapazes de atualizar-se perdendo parte de sua autonomia e prestígio como agregador de acesso online.

Instrumentos como o marketing de conteúdo ${ }^{4}$ não são utilizados para o gerenciamento de informações no website, sendo que a responsabilidade dos 
conteúdos disponíveis é mantida sob a equipe gestora- quando disponíveis. Entretanto, sabe-se que a incorporação do marketing no ambiente digital obrigatoriamente incorpora as necessidades dos usuários como ponto central para qualquer benefício e melhora do arquivo (ROSELL, 2006).

Os conteúdos específicos na área da Arquivologia são os mais destacados nas páginas verificadas. São disponibilizados os planos de classificação, gestão de documentos, tabelas de temporalidade, planos de eliminação, guias de acervos, repositórios digitais, entre outros. Para hiperlinks, observa-se o acesso a outras plataformas que possam atender à busca e ao desejo do público, entre elas: Lei de Acesso à Informação ${ }^{5}$, Arquivo Nacional $^{6}$, CONARQ $^{7}$ e o Sistema de Gestão de Documentos de Arquivo da Administração Pública $(\mathrm{SIGA})^{8}$.

Como linguagem midiática, destacam-se, além da grande presença textual, o acesso às imagens de manuscritos e a vídeos. Apenas cinco páginas virtuais utilizam de campanhas publicitárias para promoção da instituição. Foram encontrados folders de serviços ou projetos em outros websites, fotografias e vídeos de atividades realizadas, sites temáticos e ações educativas. Ainda não há uma cultura organizacional e midiática que promova os arquivos ou quaisquer organizações públicas, para que o público saiba que existem, tenham acesso às mesmas e cumpram por direito seu papel de cidadãos.

Verificou-se nos websites dos arquivos, que não são frequentes o uso de informações personalizadas, sendo que somente o e-mail é adotado como um serviço personalizado. Em alguns websites, como o Arquivo Público do Estado de São Paulo, a solicitação de cadastro refere-se às atualizações de conteúdos enviados aos e-mails particulares dos usuários. Na pesquisa personalizada, os refinamentos de busca para procura nos acervos foram de apenas sete instituições (50\%). Infere-se, então, que outros websites não possuem acervo online e muito menos um campo de busca. Em outros, existem o recurso pesquisa, mas somente como referencial externo ao site, com link que remete ao Google.

O mesmo acontece com os serviços personalizados de consulta, solicitação ou tramitação. Metade dos portais analisados (50\%) analisados 
possui um acesso às buscas personalizadas. Para Gonçalez e Jorente (2014), as informações institucionais pelos autores tidos como do patrimônio cultural, devem estar disponíveis em seus websites, para que as barreiras físicas e sociais sejam minimizadas. Todavia, os documentos não são disponibilizados, e os internautas, por sua vez, não conseguem consultar o acervo.

No que tange a relacionamentos nos websites, verificou-se as presenças de mídias sociais e alguns referenciais de auxílio para navegação na plataforma advento de ferramentas tecnológicas, o que, neste caso, possibilita que o indivíduo seja um ativo social, registrando comentários, compartilhando informações e transformando-se em protagonistas na Web 2.0. O Gráfico 1 representa todos os indicadores analisados nos websites, levando-se em consideração cada subcategoria existente (ver Figura 2).

Gráfico 1- Marketing digital em websites de arquivos públicos estaduais

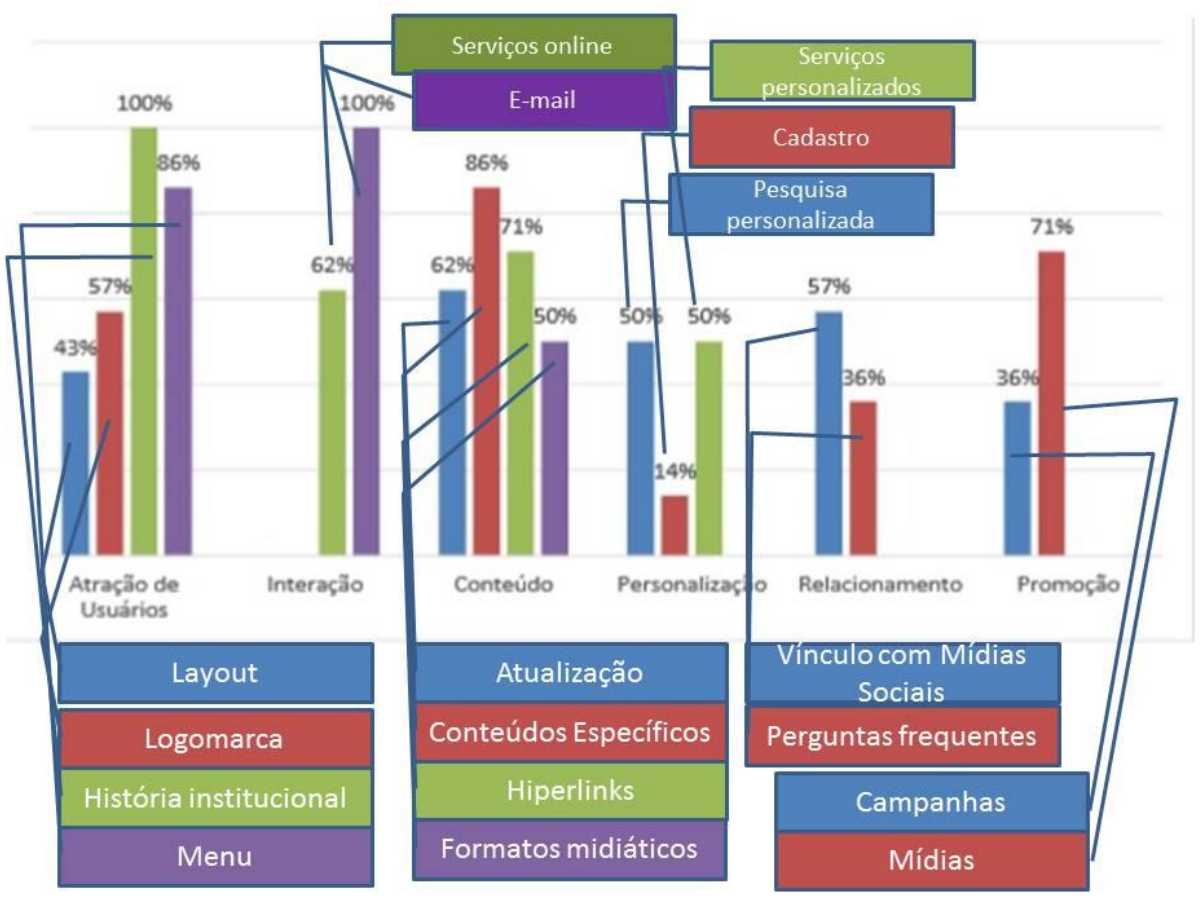

Fonte: Elaborado pelos autores.

Encontrar informações na plataforma desejada é permitir a construção de um público cativo, além de gerar oportunidades de vínculos comerciais. Um website atualizado tende a modificar a construção de conhecimento do indivíduo 
incorporando novas informações acerca das instituições a um custo financeiro apropriado às necessidades do público e do arquivo. Consequentemente, tal investimento agregará um retorno maior em visibilidade, alcance global e veiculação em outras plataformas nas quais órgãos públicos não costumam atuar. Portanto, os websites devem ser monitorados constantemente para que essas permaneçam atualizadas a partir de recursos de DI planejados em equipe multidisciplinar para uma curadoria digital (KAHN;JORENTE, 2016-2017).

O quadro analisado no Gráfico 2 demonstra que as instituições não estão preparadas para atuarem em um novo contexto de mercado aliado à web e, consequentemente, não contemplam a estrutura de marketing digital.

Gráfico 2 - Indicadores do marketing digital nos arquivos públicos estaduais

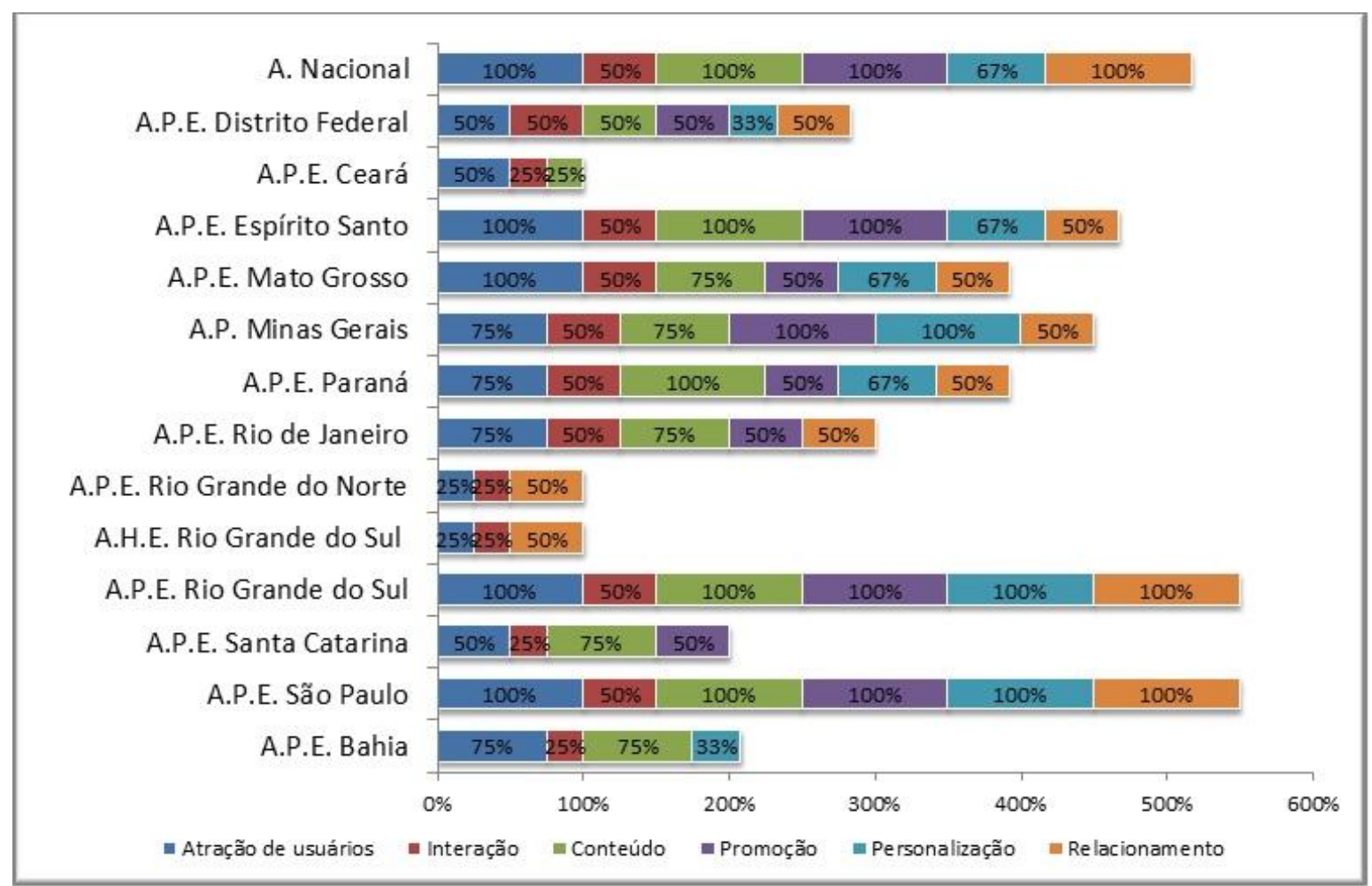

Fonte: Elaborado pelos autores.

\section{Considerações finais}

Na era digital, o acesso à informação é amplamente reforçado pela configuração que a Web 2.0 assume, desde a disponibilização das informações e transferência 
de dados até uma nova proposta de relacionamento entre o público e o mercado de informação. Assim, novas diretrizes de difusão são incluídas em rede para que os arquivos venham a se adequar às formas inovadoras de apresentação e disponibilização da informação através da internet.

Contudo, a adequação das instituições arquivísticas no ambiente digital torna-se complexa, mediante os investimentos que devem ser obtidos para tal fim. A complexidade aumentou em vista da representação do analógico para o digital, tais como softwares adequados às necessidades dos usuários e dos arquivos, uma equipe multidisciplinar que, entre outras funções, acompanhe os resultados rastreáveis do investimento, políticas que redirecionem as ações das instituições na Web e interoperabilidades com outros ambientes tecnológicos.

Sobre a "crise" do paradigma histórico no contexto informacional e tecnológico, Ribeiro (2005) destaca a emergência de uma nova perspectiva ao levantar problemáticas que norteiam o mundo tecnológico denominado "era póscustodial", pois implica na mudança de objeto de estudo e de trabalho do "documento" para a "informação", o que exige novas metodologias de investigação apropriadas a este momento.

A transferência do acervo arquivístico para a web configura um potencial que integra o uso das TIC com a gestão voltada para o acesso. As instituições arquivísticas estão presentes no ambiente web, representadas por seus websites e, assim, deveriam disponibilizar seus conteúdos informacionais e propiciar o uso de dados adequados de acordo com as necessidades dos que deles necessitem (GONÇALEZ; JORENTE, 2014).

O website amplia o paradigma de custódia e possibilita busca, acesso e uso de informações por meio dos acervos e serviços, rompendo as barreiras físicas, geográficas e econômicas de pesquisa. Entretanto, as instituições arquivísticas públicas estaduais e nacionais enfrentam uma situação de desamparo profissional, financeiro, estrutural, político, além de enfrentarem outros fatores limitadores que desencadeiam um serviço de baixa procura, sem reconhecimento social, dificultando o acesso e o uso da informação.

Tal situação espelha-se em ambiente digital, pois se o contexto físico encontra-se prejudicado, consequentemente, não poderá ser disponibilizado de 
forma ideal na Web 2.0. O quadro demonstrado nesta pesquisa confirma, claramente, que os arquivos ainda gerenciam seus conteúdos na Web 1.0, desprovidos de outros benefícios e vantagens que a rede oferece.

Destaca-se que o marketing digital requer que conteúdos informacionais inseridos nos websites sejam atualizados periodicamente. No entanto, em muitos websites de arquivos tornam-se nítidas a deficiência de agilidade de atualizações e falta de alterações constantes: o contrário do esperado em um website com vinculo governamental, que preza pela disponibilização de informações públicas e de um atendimento de qualidade, uma vez que são canais entre cidadãos e patrimônio cultural.

As novidades introduzidas pela internet levantam inquietações no que tange à disponibilização de informações, já que os websites não estão preparados para estimularem e atenderem as necessidades do público. Assim, para levantamentos futuros, as seguintes questões se impõem: "como exercer o papel de cidadão com direito à informação, sendo que as próprias páginas de arquivos governamentais não estão preparadas para atendê-los?”; "ao utilizar o marketing digital em websites de instituições públicas, quanto a informação transgride uma privacidade?"; "as instituições podem usufruir de informações de seus usuários para benefício próprio?”.

Baseando-se em empresas lucrativas, a adoção do marketing digital revela-se um aperfeiçoamento de serviços e aprimoramento de produtos e bens que, consequentemente, resultam em uma visibilidade de alcance global. Os arquivos e os arquivistas devem romper limites no horizonte de acesso à informação impostos por dificuldades e problemas em variados setores sociais para o estabelecimento de seus respectivos lugares na sociedade e atenderem, de forma estratégica, a comunidade online por meio de um plano de marketing digital voltado aos arquivos.

\section{Referências}

ALMEIDA, A. L. C. A construção de sentido sobre "quem somos" e "como somos vistos”. In: POLIZELLI, Demerval L.; OZAKI, Adalton M. (Org.). Sociedade da informação: desafios da era da informação e da gestão do conhecimento. São Paulo: Saraiva, 2008. 
AMARAL, S. A. Marketing: abordagem em unidades de informação. Brasília: Thesaurus, 1998.

AMARAL, S. A; SOUZA, K. M. L. de. Funções desempenhadas pelos websites de bibliotecas jurídicas governamentais brasileiras. Investigación

Bibliotecológica, Ciudad de México, v. 22, n. 46, p. 165-186, sept./dic. 2008.

ANGEHRN, A. Sites web de alta tecnologia e alto contato. In: J. L. Kellog Graduate School of Management. Dominando o marketing. São Paulo: Makrn books, 2001. p. 270 - 274.

ARAÚJO, W. S.; SILVA, M. B. A importância do marketing de relacionamento na gestão de bibliotecas universitárias. In: CONGRESSO BRASILEIRO DE BIBLIOTECONOMIA, DOCUMENTAÇÃO E CIÊNCIA DA

INFORMAÇÃO, 2013. Anais... São Paulo: FEBAB, 2013. p. 2821-2825.

BLAYA PEREZ, C. Marketing e difusão. In: arquivos. Santa Maria: Ed. da UFSM, 2008. p. 30-38.

BRASILEIRO, F. S.; FREIRE, G. H. A. O marketing e a arquitetura da informação para web no contexto do processo de mediação da informação. Biblionline, João Pessoa, v. 8, n. esp., p. 161-174, 2012. Disponível em: <http://periodicos.ufpb.br/ojs/index.php/biblio/article/view/14200/8106>. Acesso em: 18 ago. 2015.

CASTELLS, M. A galáxia da internet: reflexões sobre a internet, os negócios e a sociedade. Rio de Janeiro: Zahar, 2001.

CHAIM, R. M. Estratégias de marketing na internet para website. In:

AMARAL, Sueli A. (Org.). Marketing na ciência da informação. Brasília: Ed. Universidade de Brasília, 2007. 230 p.

CHLEBA, M. Marketing digital: novas tecnologias e novos modelos de negócios. São Paulo: Futura, 1999.

FLEURY, A. L. Dinâmicas organizacionais em mercados eletrônicos. São Paulo: Atlas, 2001.

GONÇALEZ, P. R. V. A.; JORENTE, M. J. V. Disseminação da informação nos websites dos arquivos permanentes e as novas tecnologias de informação e comunicação. Tendências da Pesquisa Brasileira em Ciência da Informação, João Pessoa, v. 7, n. 1, jan./jun. 2014. Disponível em: <inseer.ibict.br/ancib/index.php/tpbci/article/viewFile/130/172>. Acesso em: 9 nov. 2015.

HAIR, J. F. Fundamentos de pesquisa de marketing. 3. ed. Porto Alegre: AMGH, 2014. 
KAHN, K.; JOERENTE, M. J. V. O papel do design da informação na curadoria digital do Museu da Pessoa. InCID, Ribeirão Preto, v. 7, n. 2, p. 23-39, set. 2016/fev. 2017.

KOTLER, P.; ARMSTRONG, G. Introdução ao marketing. Rio de Janeiro: LTC, 1997.

LÉVY, P. Cibercultura. 2. ed. São Paulo: Ed. 34, 2000.

MENEZES, P. L. O processo de difusão desenvolvido pelos arquivos públicos estaduais da região sul do Brasil. Ponto de Acesso, Salvador, v. 6, n. 3, p. 4771, dez. 2013. Disponível em:

<https://portalseer.ufba.br/index.php/revistaici/article/viewArticle/6164>. Acesso em: 9 jan. 2017.

OLIVEIRA, Â. M.; PEREIRA, E. C. Marketing de relacionamento para a gestão de unidades de informação. Informação \& Sociedade: Estudos, João Pessoa, v. 13, n. 2, p. 13-36, jul./dez. 2003.

RIBEIRO, F. Os arquivos na era pós-custodial: reflexões sobre a mudança que urge operar. Boletim cultural, Vila Nova de Famalicão, 2005. Disponível em: <http://ler.letras.up.pt/uploads/ficheiros/artigo10091.pdf>. Acesso em: $10 \mathrm{dez}$. 2015.

ROSELL, A. T. Márquetin y archivos. España: Trea. 2006.

STRAUSS, J; FROST, R. E-marketing. 7 ed. [S.1.]: Prentice Hall, 2012.

VAN DEN AKKER, C. et al. Digital hermeneutics: Agora and the online understanding of cultural heritage. In: ASSOCIATION FOR COMPUTING MACHINERY. Proceedings of the 3rd International Web Science Conference. New York: ACM, 2011.p. 10.

ZEISSER, M.; WAITMAN, R. Organizing today for the digital marketing of tomorrow. Journal of Interactive Marketing, v. 12, n. 1, Winter 1998.

\title{
Digital marketing indicators to state public websites archives
}

\begin{abstract}
The web as a framework for new forms of communication and informational interaction allows to enhance the archival units. The marketing adapts to digital media in order to conquer other markets with better precision and meet the audience's needs. The research is justified by the few studies of this nature in the information science field and it is believed that the results
\end{abstract}


support the development of digital marketing for informational institutions. Thus it tends to be problematic the access research to information through Digital Marketing for state public archives front. The purpose of the investigative study proposed is to analyze websites of Brazilian state public records in order to verify the institutional promotion through digital marketing and informational dissemination carried out through the virtual spaces while forming an electronic environment. The study is a qualitative approach, with case study methodology of the digital environment of the information units carrying out a comparative analysis of the websites of state public archives.

Keywords: Digital marketing. Dissemination. Indicators. Archive.

Recebido em: 11/09/2016

Aceito em: 11/01/2017

${ }^{1}$ KOTLER, P. Marketing para organizações que não visam lucro. São Paulo: Atlas, 1978. Apud Amaral, 1998.

${ }^{2}$ Disponível em <http://www.conarq.gov.br/>. Acesso em: 9 jan. 2017.

${ }^{3}$ A filosofia Web 2.0 prima pela facilidade na publicação e na rapidez no armazenamento de textos e ficheiros, ou seja, tem como principal objetivo tornar a Web um ambiente social e acessível a todos os utilizadores, um espaço onde cada um seleciona e controla a informação de acordo com suas necessidades de desejos (COUTINHOS; BOTTENTUIT JUNIOR, 2007, p. 13).

${ }^{4}$ Content Marketing baseia-se na criação, gestão e partilha de conteúdos relevantes e atrativos para os utilizadores, ou seja, a produção de conteúdos com o objetivo especifico de fazer com que os utilizadores adquiram os produtos ou bens de uma data empresa. [...] Estes conteúdos devem ser diversificados de forma a captar a atenção, o interesse e despertar emoções e sentimentos em inúmeros visitantes e, assim, torná-los seguidores da página em questão (COSTA, 2013, p. 14).

${ }^{5}$ Disponível em: <http://www.acessoainformacao.gov.br/>. Acesso em: 11 abr. 2016.

${ }^{6}$ Disponível em: <http://www.arquivonacional.gov.br/>. Acesso em: 11 de abr. 2016.

${ }^{7}$ Disponível em: <http://www.conarq.arquivonacional.gov.br/>. Acesso em: 11 de abr. 2016.

${ }^{8}$ Disponível em: <http://www.siga.arquivonacional.gov.br/>. Acesso em: 11 de abr. 2016. 